\title{
DO CHILDREN USE "FINE" OSTENSIVE COMMUNICATION?
}

\author{
HARUMI KOBAYASHI $^{* 1}$, and TETSUYA YASUDA ${ }^{1}$ \\ *Corresponding Author: h-koba@mail.dendai.ac.jp \\ ${ }^{1}$ Tokyo Denki University, Saitama, Japan
}

Ostensive communication is a type of communication in which the speaker presents certain information with communicative intention, i.e., with evidence of intention to convey information to the receiver (Wilson \& Sperber, 2012). Ostensive communication is claimed to be unique to human communication (Senju \& Csibra, 2008; Tomasello, 2008) and it is possibly the foundation of human language (Scott-Phillips, 2015). Ostensive communication about specific aspects of the environment is essential. For example, we need to correctly specify and convey information about parts, including object parts, of the environment in many situations, such as "The handle of the knife is fragile, so it needs fixing" or "The dog's tail may be injured, so it needs care." We wish to claim that humans needed more "fine" ostensive communication skills to explicitly convey information on object parts, and this is one reason why language evolved.

If fine ostensive communication is important for the evolution of language, the course of the development of these skills in children may provide precious information about the mechanism of ostensive communication. We examined 4and 6-year-olds' ability to recognize and control ostensive cues using the "teaching part names paradigm" that we originally developed in this study. Teaching seems to be an ultimate form of ostensive communication because, in addition to presenting the clear intention of conveying information to the receiver, the speaker must consider the receiver's viewpoint, knowledge, and skills, and appropriately control her own teaching behavior.

Eleven 4-year-old and 12 6-year-old preschoolers participated in the experiment. Two types of pointing gestures, namely, touch-pointing and $7 \mathrm{~cm}$ distance pointing, were used in the experimental task. In this task, the experimenter introduced a lion puppet as a language learner and asked the child to teach certain word meanings to the puppet. Then the experimenter showed the child an experimental puppet (e.g., a bear) that holds an object (e.g., a patrol car). The experimenter then pointed with either touching or without touching (with $7 \mathrm{~cm}$ distance to the object part) one of the tires of the patrol car with her 
finger, and said in Japanese, "This is agu (nonsense syllable) in a foreign language." Thus, the critical object part was embedded in an object that was held by a puppet. Then she asked the child to teach the nonsense syllable to the "learner puppet" (production trial). The child was also asked to respond to "What is agu?" either using language or gestures (comprehension trial). The child's teaching behavior (pointing with touching or close to the object part/pointing without touching the object part/showing to the puppet/other) and responses were analyzed.

In the gesture production trial, a 2 (Age: 4 and 6 year-olds) $\times 2$ (Teaching: $7-\mathrm{cm}$ pointing and touch-pointing) mixed two-way ANOVA was performed, with each type of gesture when the children taught part names (touch-pointing, showing) as dependent measures. Other gestures were rare, and therefore, they were excluded from the present analysis. There was a significant main effect of age and a significant interaction of age $\times$ teaching. The simple main effect of the age $\times$ teaching interaction revealed that 6 -year-olds pointed to the object more frequently than the 4-year-olds did in the 7-cm pointing teaching. In the comprehension trial, 6-year-olds successfully guessed more part names when the experimenter touch-pointed at the object part than when she engaged in 7 $\mathrm{cm}$ pointing.

The present findings showed that 6-year-olds better understand and control ostensive cues in teaching word meanings than 4-year-olds do. The older children seemed to implicitly know that different pointing gestures are appropriate for teaching part and whole labels. However, even 6-year-olds who understood the meaning of touch-pointing did not touch-point at the object part producing the part name if the object part was presented in the embedded situation. This result suggests that "fine" ostensive communication, including the appropriate use of showing, is in the developmental state in 4-year-olds. The study also seems to suggest that ostensive cue control precedes language control.

\section{References}

Scott-Phillips, T. (2015). Speaking our minds: Why human communication is different, and how language evolved to make it special. UK: Palgrave MacMillan.

Senju, A., \& Csibra, G. (2008). Gaze following in human infants depends on communicative signals. Current Biology, 18(9), 668-671.

Tomasello, M. (2008). Origins of human communication. Cambridge, MA: Harvard University Press.

Wilson, D., \& Sperber, D. (2012). Meaning and relevance. Cambridge: Cambridge University Press.

\section{Acknowledgements}

This work was supported by MEXT/JSPS KAKENHI Grant Number JP17H06382 in \#4903 (Evolinguistics), JP 16K04318, and JP 17K04949. 